\title{
Reinstatement of postresponse stimuli prior to reward in delayed-reward discrimination learning by pigeons
}

\author{
PATRICIA B. CRONIN \\ Cornell College, Mount Vernon, lowa 52314
}

\begin{abstract}
Delayed-reward learning in pigeons was examined using a simultaneous red-green visual discrimination task in which the conditions during the delay interval were varied between groups. The nondifferential group received training in which the stimulus present during the 1-min delay was the same following a peck on the correct and incorrect colors. The other three groups received 1-min delay training in which different stimuli occurred in the delay interval following correct and incorrect choices. The differential group received continuous, differential stimuli during the delay. The reinstatement group received the differential stimuli in the $10 \mathrm{sec}$ immediately following the choice and during the last $10 \mathrm{sec}$ of the delay. The reversedcue group was treated in the same way, except that the 10-sec delay stimulus immediately following an incorrect response was also presented for $10 \mathrm{sec}$ prior to reward on correct choices, and the stimulus following a correct response also occurred $10 \mathrm{sec}$ before nonreward on incorrect choices. Nondifferential birds failed to learn the discrimination, while differential and reinstatement birds learned it readily. The reversed-cue birds learned to choose the incorrect stimulus. Differential and reinstatement birds showed no decrement in performance when the delay was increased to $2 \mathrm{~min}$. These findings suggest that similarity of prereward and postresponse delay stimuli controls choice responding in long-delay learning, a finding compatible with both memorial and conditioned reinforcement interpretations.
\end{abstract}

There has been a resurgence of interest in delayedreward learning and the processes underlying it. Lett (1979), Roberts (1976), and Spear (1978) have all suggested that long-delay learning is attributable to the memorial reinstatement of the choice response at the time of reward. In a simultaneous visual-discrimination task employing delayed reward, the subject makes a choice response and may associate the delay stimuli that immediately follow with that response. Similar delay stimuli immediately preceding reward may reactivate or retrieve the memory of that choice response according to a memory reactivation interpretation. It is this contiguity between the memory of the correct response and reward that produces a preference for S+. Memorial reactivation of the choice response and its contiguous delay stimuli at the time of reward is facilitated by the similarity of the postresponse and prereward stimuli.

This study is based on a doctoral dissertation submitted to the Department of Psychology, Kansas State University, in partial fulfillment of the requirements for the $\mathrm{PhD}$ degree and was supported by Grant GB-27595 awarded to Kansas State University, Charles C. Perkins, principal investigator. Special appreciation is expressed to Dr. Perkins for his helpful advice and encouragement throughout all phases of this experiment. Much of this material was presehted as a paper at the 1976 meeting of the Midwestern Psychological Association. Reprints may be obtained from the author, Department of Psychology. Cornell College, Mount Vernon, lowa 52314.
Although the memorial reactivation interpretation may be viewed as incompatible with Spence's (1947) classic interpretation of delayed-reward learning, both interpretations emphasize the similarity of postresponse and prereward delay stimuli. Spence assumed that reinforcement was immediate and that if learning occurred in a delayed-reward procedure, then conditioned reinforcement was present. According to Spence's conditioned reinforcement interpretation, learning occurs when the postresponse and prereward stimuli following St are similar and discriminable from those delay stimuli following $S-$, the incorrect choice stimulus.

One delayed-reward procedure which should produce good learning according to either theoretical view, but has, with the exception of a few studies (e.g., Trenholme \& Baron, 1975), received little attention, is referred to here as a "cue reinstatement" procedure. In this discrimination procedure, the differential delay stimuli following $\mathrm{S}+$ and $\mathrm{S}-$ are reinstated immediately prior to reward and nonreward, respectively, following a nondifferential middle-delay period. Obviously, this procedure has utility for assessing the role of conditioned reinforcement and memory retrieval in delayed-reward learning, particularly because choice, delay, and trial outcome all occur in the same environment.

In the present experiment, four groups of pigeons were given 1-min delayed-reward training in a two-key pigeon chamber. Treatment differed only with regard to the kind of delay stimuli present. The nondifferential 
group received training in which the same continuous environmental conditions were present throughout the delay intervals following both correct and incorrect responses. For the differential group, one continuous stimulus followed the correct response and a different continuous stimulus followed an incorrect response. The reinstatement group received differential delay stimuli of a noncontinuous nature. A 10-sec stimulus followed the correct response and was later reinstated for the last $10 \mathrm{sec}$ of the delay interval. An incorrect response was followed by a different 10 -sec delay stimulus which was reinstated for the last $10 \mathrm{sec}$ of the delay. Finally, the reversed-cue group received training similar to that of the reinstatement group in that differential $10-\sec$ delay stimuli immediately followed correct and incorrect responses. However, in the reversed-cue condition, the stimulus immediately following a correct response was presented for the last $10 \mathrm{sec}$ of the delay following an incorrect response, and the stimulus immediately following an incorrect choice was presented for the last $10 \mathrm{sec}$ of the delay following a correct choice. If, as both the memorial and conditioned rein forcement accounts predict, delayed-reward visual discrimination learning in the pigeon is strongly controlled by the relationship between postresponse and prereward stimuli, then the reinstatement group will demonstrate a preference for $\mathrm{S}+$ as rapidly as the differential group. Similarly, both of these interpretations predict that the reversed-cue group will acquire a preference for $\mathrm{S}-$ equal to the reinstatement group's St preference. According to the conditioned reinforcement view, responding to $S$ - receives immediate conditioned reinforcement, strengthening preference for $S$ - in the reversed-cue birds; according to the memorial view, memory of the S- response is reinstated just before reward, conditioning a preference for $\mathrm{S}-$ in these birds. Previous studies, employing a somewhat similar reversedcue condition (Bauer \& Lawrence, 1953; Lawrence \& Hommel, 1961), obtained an St preference but failed to provide strict environmental cue reinstatement. In both cases, alleyway colors were reinstated in otherwise discriminably different goalboxes, facilitating a discrimination between otherwise similar prereward and postresponse conditions. In contrast, the present study provides strict reinstatement of postresponse environmental stimuli before reward.

\section{METHOD}

\section{Subjects}

Sixteen experimentally naive domesticated pigeons were housed individually in a continually illuminated colony room. They were maintained at $75 \%$ of their free-feeding weights by grain obtained during daily experimental sessions and, when necessary, by supplemental feeding immediately after experimental sessions.

\footnotetext{
Apparatus

Two identical $33 \times 38 \times 31 \mathrm{~cm}$ two-key plywood experimental pigeon chambers, painted flat gray throughout and located in sound-attenuating cubicles, were used. Each box was equipped with two Gerbrands pigeon-response keys (spaced $5 \mathrm{~cm}$ apart,
}

with two Gerbrands pigeon-response keys (spaced $5 \mathrm{~cm}$ apart, center to center), $21 \mathrm{~cm}$ above the false floor. Reward was provided by 4 -sec access to grain in a $5 \times 4 \mathrm{~cm}$ opening located midway between and $13 \mathrm{~cm}$ below the keys. A 1.1-W, 24-V incandescent light illuminated the feeder opening during grain presentations. Response keys were illuminated by Industrial Electronic Engineers multiple stimulus projectors, and general illumination was provided by lighting one of three $115-\mathrm{V}, 6-\mathrm{W}$ yellow, blue, and white houselights mounted above a round translucent window centered in the ceiling. Extraneous sounds were masked by white noise and the sound of an exhaust fan (inside chamber noise level was $90 \mathrm{~dB}$, re $20 \mathrm{~N} / \mathrm{m}^{2}$, measured with a General Radio (o. sound-level meter). A $10 \times 6 \mathrm{~cm}$ window in the door of the chamber permitted observation of the birds during training sessions. A keypeck with a force of at least $.1 \mathrm{~N}$ on illuminated keys produced an audible relay click. Keypecks were recorded on digital counters, and all stimulus events and keypecks were recorded on strip charts. Recording and standard electromechanical programming equipment were located adjacent to the experimental room.

\section{Procedure}

Pretraining. Pretraining established pecking to illuminated keys and maintained this pecking as the delay between key illumination and grain delivery increased. Except during feeder presentation, when only the feeder light was on, a white houselight illuminated the chamber throughout pretraining. The pigeons were initially trained to eat whenever the grain hopper was presented. Then each pigeon advanced through three phases of pretraining designed to establish pecking to intermittently presented keylights. In each session, the keylight stimulus occurred equally often on the left and right keys, with no more than four consecutive presentations on the same key. A variable 2-min intertrial interval (ITI) constructed from Fleshler and Hoffman (1962) schedules was employed for all of pretraining.

In Phase 1, the key was illuminated with white light for a maximum of $10 \mathrm{sec}$ on 20 trials in each session. At the end of the $10-\mathrm{sec}$ trial, or immediately following a peck on the lighted key, the key and the houselight were darkened and grain was presented in the lighted hopper for $4 \mathrm{sec}$. The houselights were turned on again following grain delivery, but the keys remained dark during the ITI. As soon as a bird pecked at least once on every trial in a session (requiring one to four sessions), the maximum keylight duration on each trial was increased to $15 \mathrm{sec}$ and grain was produced by the first keypeck $5 \mathrm{sec}$ or more after key illumination (FI $5 \mathrm{sec}$ ). On trials when the FI 5 -sec requirement was not met, grain was presented at the end of $15 \mathrm{sec}$. After one or two sessions, all pigeons met the criterion of pecking at least once on each trial of a session. Finally, the FI requirement was increased to $10 \mathrm{sec}$, where it remained until all birds had met a criterion of at least one peck on every trial of a session (one to three sessions).

Phase 2 was designed to establish pecking to red and green keylight stimuli. On each of 20 trials in each session, both keys were simultaneously illuminated, one red and the other green. Each key color appeared an equal number of times on the left and right keys in every session, with no more than four consecutive presentations of the same color on the same key. Initially, a single peck to either key color changed the stimulus on the pecked key to white for $10 \mathrm{sec}$ and immediately darkened the other key. Grain followed the 10 -sec white delay stimulus. Responses to the white key provided a feedback click but had no other effect. Within two sessions, all birds completed the 20 trials in $2 \mathrm{~h}$. Subsequently, an FI 4-sec response requirement was introduced during presentation of the red and green stimuli. In this case, both keys remained illuminated until the response requirement was met on either key, at which time the color on the pecked key was changed to white and the nonpecked key was darkened.

Phase 3 of pretraining was intended to equalize pecking rates to the red and green stimuli. As before, red and green key colors were presented simultaneously, one on each key; how- 
ever, the change to a white keylight was contingent upon the first response to only one of the keys on an FI 4-sec schedule. This contingency was set up on the red and green key equally often in a random sequence, with the restriction that neither the red nor the green stimulus appear on the same key more than four times in succession. Both keys remained illuminated with the red and green stimuli until the response requirement was met or the session terminated after $2 \mathrm{~h}$. Initially, grain was presented upon the termination of the 10 -sec white delay stimulus following half of the effective responses to each color. Once a bird completed the trials scheduled within a 2 -h session, the duration of the white delay stimulus was increased, in order, from $10 \mathrm{sec}$ to $15,30,45$, and finally $60 \mathrm{sec}$. The number of trials scheduled per session was 24 for sessions with 10- or 15-sec delay of reward and 16 for the 30-, 45-, and 60-sec delay. All birds successfully completed training at each delay interval in one to three sessions.

Training. The birds were assigned randomly to four groups $(\mathrm{Ns}=4)$, for which certain procedures were common. During the variable ITI, averaging $2 \mathrm{~min}$ in duration, the keys were dark and silent. Trials began with the simultaneous illumination of the red and green response keys; each color was presented an equal number of times on the left and right keys in an irregular order, with the restriction that no more than four consecutive presentations be on the same side. The first response to either key $4 \mathrm{sec}$ after onset of the choice stimuli changed the stimulus on the pecked key from red or green to white for $60 \mathrm{sec}$ and darkened the other key. Responses on one key color $(\mathrm{S}+)$ produced grain after the delay; responses on the other color (S-) were never followed by grain, as Figure 1 indicates. The stimulus-reward contingency was counterbalanced across subjects in each group. Also common to all groups was a forcedtrials procedure designed to equate the number of exposures to $\mathrm{S}+$ and $\mathrm{S}-$ trials. When a bird had completed $10 \mathrm{~S}+$ or $10 \mathrm{~S}-$ trials, the remaining of the 20 trials in that session were "forced" to the other discriminative stimulus. If a bird failed to complete all 20 trials within $2 \mathrm{~h}$, the session immediately terminated if (a) one or both discriminative stimuli had been on the key(s) for $45 \mathrm{sec}$ or (b) an ITI was in effect.

The groups differed with respect to the nature of houselight stimuli added to the delay interval. These conditions are summarized in Figure 1. For the nondifferential group, half the birds always received a blinking yellow houselight during the 1-min delay following effective responses to either $S+$ or $S-$; the other birds received a constant blue houselight during the delay. Food followed the delay period if the effective response had been to $S+$. If the response had been to S-, ITI conditions were instituted immediately after the delay, adding $4 \mathrm{sec}$ to the ITI.

For the remaining three groups, the houselight stimuli presented during all or part of the delay depended on whether the effective response had been to $\mathrm{S}+$ or $\mathrm{S}-$. The delay stimuli were counterbalanced across birds in each group. For the differential group, the constant blue houselight was present during the delay following one keylight, and a blinking yellow houselight followed a choice response to the other keylight. The reinstatement group received differential delay stimuli in the $10 \mathrm{sec}$ immediately following $\mathrm{S}+$ and $\mathrm{S}-$, and the same stimuli were reinstated in the last $10 \mathrm{sec}$ of the delay period following a 40-sec white houselight period (i.e., the normal chamber condition). The reversed-cue group received training similar to the reinstatement group's, except that the $10 \mathrm{-sec}$ delay stimuli which occurred at the beginning and end of each delay interval were not identical; immediately following a choice response to $S+$, the $10-\mathrm{sec}$ houselight stimulus was the same one that immediately preceded nonreward on S- trials, and the stimulus immediately following a choice of $S$ - was the same one that immediately preceded food when $S+$ was chosen

Birds in the nondifferential, differential, and reinstatement groups received a minimum of 15 training sessions. In addition, each bird was trained until it met the criterion of two or fewer choices to S- (a minimum of $80 \%$ correct) during three consecutive sessions or until 30 training sessions were completed, which-

\section{NONDIFFERENTIAL}

\section{DIFFERENTIAL}
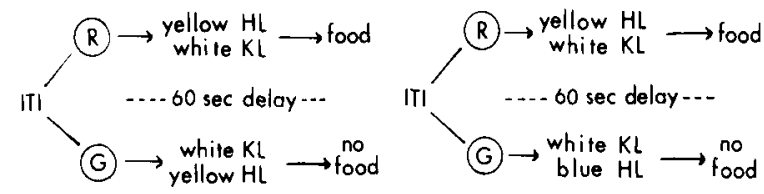

REINSTATEMENT

REVERSED CUE

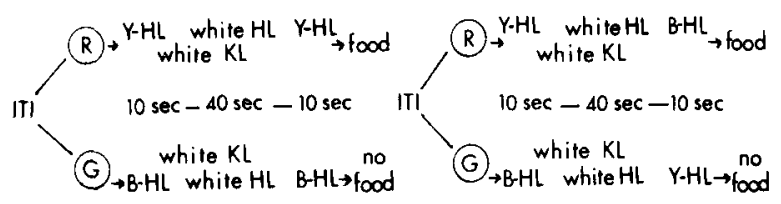

Figure 1. Summary of the 1-min delay training procedure for the reinstatement, differential, nondifferential, and reversed-cue groups. The following conditions were common to all groups: (1) A variable 2-min ITI was used during which the keys were dark and silent; (2) assignment of the red (R) or green (G) key color as $\mathbf{S}+$ or $\mathbf{S}$ - was counterbalanced across birds in each group; (3) differential houselight (HL) delay stimuli were also counterbalanced within a group and consisted of a blinking (1-sec-on, .5-sec off) yellow houselight (Y-HL) or a constant blue houselight (B-HL); (4) a white houselight (W-HL) was normally present in the chamber except when the differential houselight delay stimuli were present or when food was presented; and (5) a white keylight (KL) remained on the pecked key throughout the delay in every group.

ever came first. After reaching criterion for the 1-min delay training, birds in the nondifferential, differential, and reinstatement groups received five sessions of training with a 2-min delay. For the reinstatement group, the delay was increased by lengthening the middle, nondifferential segment of the delay from $\mathbf{4 0}$ to $100 \mathrm{sec}$. Delay cues following the choice response, and later reinstated before reward and nonreward, each remained $10 \mathrm{sec}$ in duration. Maximum session length for the 2-min delay training was increased from 2 to $2.5 \mathrm{~h}$. Reversed-cue birds received 15 sessions of 1-min delay training.

\section{RESULTS}

All birds progressed rapidly through pretraining and displayed no systematic differences in rate of pecking to the red and green colors or to the left and right keys by the end of pretraining.

The proportion of trials on which the pigeons met the contingency on (i.e., chose) the S+ key during the first 10 trials was analyzed. The same conclusions are reached whether the analyses are based on this measure or on performance over all free-choice trials in each session.

Figure 2 presents the mean proportion of S+ choices by each group as a function of training sessions. The nondifferential group responded at essentially chance level throughout the 1 - and 2-min delay conditions. In contrast, a clear preference for S+ developed across the 151 -min delay sessions for the reinstatement and differential groups. During Sessions 13, 14, and 15, every bird in the nondifferential group chose $\mathrm{S}-$ on more trials than did any bird in the differential or reinstatement groups. Terminal performance for the differ- 


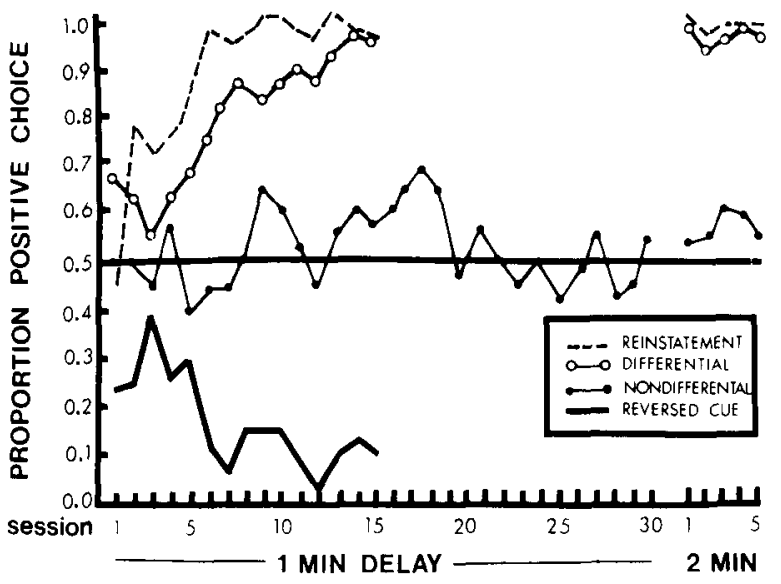

Figure 2. Mean proportion of $5+$ choices for the reinstatement. differential, and nondifferential groups in 1- and 2-min delay training. The reversed-cue group was trained only with the 1-min delay.

ential and reinstatement groups was above .9 , and a Groups by Sessions ( 2 by 15 ) ANOVA performed on these birds' individual choice indices revealed only a significant sessions effect $[F(14,84)=10.6, p<.01]$. This analysis supports the conclusion that acquisition and terminal performances in the 1-min delay condition were similar for the differential and reinstatement groups.

Figure 2 shows that the reversed-cue group responded predominantly to $S-$. One pigeon's data are not included in this group's means, plotted for Sessions 11 through 15, or in any statistical analyses involving these sessions. That pigeon responded only to S- after Session 5, and it ceased all pecking after Session 10. A mean choice index was derived for Sessions 11 through 15 for each bird in the nondifferential and reversed-cue groups. The reversed-cue group chose $\mathrm{S}-$ more often (mean choice ratio $=.09$ ) than did the nondifferential group (mean choice ratio $=.49)[\mathrm{t}(5)=4.03, \mathrm{p}<.025]$.

The reinstatement and reversed-cue groups' performances were analyzed further to determine if both groups selected equally the choice stimulus that was immediately followed by the prereward stimulus. Each reversed-cue bird's daily choice index was subtracted from 1.0, such that, for example, a choice index of .2 became .8 and an index of 0.0 became 1.0. An unequal-N Groups by Sessions ANOVA was performed on these derived values and showed no difference between the reinstatement and reversed-cue groups $(\mathrm{F}<1)$; nor was there a significant Groups by Sessions interaction $[F(14,70)=1.11, p>.05]$. The significant sessions factor confirmed that the birds selected the stimulus immediately followed by the prereward delay stimulus more often as training progressed $[F(14,70)=$ $3.21, \mathrm{p}<.01]$.

Each nondifferential, reinstatement, and differential bird's latency to complete the choice response to St, measured to the nearest second, and each reversed-cue bird's latency to choose S- on each of the first 10 trials of Sessions 11 through 15 were transformed to $\log _{10}$. A significant groups effect $[\mathrm{F}(3,11)=6.87, \mathrm{p}<.01]$ was obtained when an unequal-N ANOVA was performed on the individual bird's daily mean $\log$ latencies for Sessions 11 through 15. Subsequent Scheffé posttest analyses revealed that the nondifferential birds' latencies to $\mathrm{S}+$ were significantly longer $(p<.05)$ than those of the other three groups, whose latencies did not differ from each other $(p>05)$. While the reversed-cue group's latency was slightly longer $($ mean $=18.62 \mathrm{sec})$ than the reinstatement group's (mean $=13.58 \mathrm{sec}$ ), this difference was not significant $(p>.05)$. To ensure that this difference was, indeed, unreliable, these two groups' data were analyzed further by an unequal- $\mathrm{N}$ Groups by Sessions ( 2 by 5 ) ANOVA. Groups $[\mathrm{F}(1,5)=$ $1.33, p>.05]$, sessions $(F<1)$, and the interaction $(F<1)$ were insignificant. In sum, the reversed-cue birds responded as quickly to $\mathrm{S}$ - as reinstatement and differential birds did to $\mathrm{S}+$.

Because there was a 2-h session limit, the number of $\mathrm{S}+$ and $\mathrm{S}$ - trials could vary across groups and across training. Table 1 presents the mean number of total St and S- trials completed for blocks of five sessions for the 1- and 2-min delay training. In general, birds completed 20 daily session trials during the first block of the 1-min training, receiving equal exposure to the delay stimuli that immediately preceded reward and nonreward. The number of $\mathrm{S}-$ trials completed by

Table 1

Mean Number and Standard Deviations of Trials Completed to S+ and S- for the Reinstatement, Differential, Reversed Cue, and Nondifferential Birds for Blocks of Five Sessions of the 1- and 2-Min Delay Training

\begin{tabular}{|c|c|c|c|c|c|c|c|c|c|c|c|c|c|c|c|c|}
\hline \multirow[b]{4}{*}{ Group } & \multicolumn{12}{|c|}{ 1-Min Delay } & \multirow{2}{*}{\multicolumn{4}{|c|}{$\begin{array}{c}\text { 2-Min Delay } \\
(\text { Block 1) }\end{array}$}} \\
\hline & \multicolumn{4}{|c|}{ Block 1} & \multicolumn{4}{|c|}{ Block 2} & \multicolumn{4}{|c|}{ Block 3} & & & & \\
\hline & \multicolumn{2}{|c|}{$S+$} & \multicolumn{2}{|c|}{ S- } & \multicolumn{2}{|c|}{ S+ } & \multicolumn{2}{|c|}{ S-- } & \multicolumn{2}{|l|}{ S+ } & \multicolumn{2}{|c|}{ S- } & \multicolumn{2}{|c|}{ S+ } & \multicolumn{2}{|c|}{ S- } \\
\hline & Mean & $\mathrm{SD}$ & Mean & $\mathrm{SD}$ & Mean & $\mathrm{SD}$ & Mean & $\mathrm{SD}$ & Mean & $\mathrm{SD}$ & Mean & $\mathrm{SD}$ & Mean & SD & Mean & SD \\
\hline Reinsta & 9.50 & 1.40 & 6.70 & 3.18 & 10.00 & .00 & 3.15 & 3.00 & 10.00 & .00 & 2.50 & 2.21 & 9.90 & .30 & 1.00 & \\
\hline Differential & 10.00 & .00 & 9.90 & .45 & 10.00 & .00 & 7.85 & 1.93 & 10.00 & .00 & 4.85 & 3.74 & 9.90 & .45 & 2.55 & \\
\hline Reversed Cue & 9.90 & .45 & 10.00 & .00 & 6.55 & 4.46 & 8.55 & 2.60 & $5.93^{*}$ & 4.49 & 9.40 & 1.05 & & & & \\
\hline Nondifferential & 10.00 & .00 & 9.80 & .89 & 9.80 & .89 & 9.80 & .70 & 9.75 & .62 & 9.60 & 1.23 & 9.25 & 1.65 & 8.97 & 2.0 \\
\hline
\end{tabular}

Note-Reversed cue birds were not given 2-min delay training.

* One bird's data are not included in this block. 
reinstatement and differential birds and S+ trials completed by reversed-cue birds declined after Session 4 . Except for one reversed-cue bird, birds in the reinstatement, differential, and reversed-cue groups continued responding daily to at least one trial terminating with nonreward.

The birds' pecking during the delay interval was examined to determine if the birds in the groups given differential delay stimuli demonstrated an inhibition-ofdelay effect, that is, an increase in keypecking as the delay progressed. For each bird, mean daily pecks/second were obtained during the first $10 \mathrm{sec}$, the middle $40 \mathrm{sec}$, and the last $10 \mathrm{sec}$ of the delay following all completed $\mathrm{S}+$ and $\mathrm{S}$ - trials for Sessions 11 through 15. Table 1 indicates the mean number of trials on which these rate data are based. Birds did not respond differentially during these delay periods, nor did the groups' performances differ: (a) An unequal-N, 4 by 3 by 2 (Groups by Delay Period by Positive-Negative Delay) ANOVA on individual bird's pecking rates, (b) additional Delay Period by Positive-Negative Delay ANOVAs performed separately for each group, and (c) ANOVAs based on each group's S+ (S- for reversed-cue birds) delay responding all failed to demonstrate any significant effects $(p>.05)$. While birds continued pecking the white keylight during the delay periods, rates were fairly low, with average group pecking rates ranging from .019 to $.622 \mathrm{pecks} / \mathrm{sec}$.

Increasing the delay from 1 to $2 \mathrm{~min}$ had no detrimental effect on the reinstatement and differential groups' choice performances. As seen in Figure 2, both groups continued to select S+ on at least $90 \%$ of the first 10 trials during each session, while the nondifferential group maintained its chance-level performance. Analyses of individual bird's transformed $\left(\log _{10}\right)$ response latencies to $S+$ for the first 10 trials of each session supported these choice ratio data. Similar to the 1-min delay results, an ANOVA and subsequent Scheffé posttests confirmed that the nondifferential bird's latencies were considerably longer $(p<.01)$ than were those of the differential and reinstatement groups, which did not differ from each other $(p>.05)$. While latencies for the differential and reinstatement birds increased slightly when the 2-min delay was introduced, a Delay Length by Groups by Sessions ( 2 by 3 by 5) ANOVA found this increase to be nonsignificant. Neither the delay effect $(F<1)$ nor the Delay by Groups interaction $[F(2,9)=1.389, p>.05]$ was significant.

\section{DISCUSSION}

The reinstatement, differential, and reversed-cue groups' performances demonstrated that choice responding was controlled by the similarity of prereward and postresponse stimuli. All of these groups chose predominantly the stimulus that was followed by the postresponse stimulus that immediately preceded reward.
The nondifferential group, provided with no external differential delay cues, failed to learn. Increasing the delay to $2 \mathrm{~min}$ did not attenuate the reinstatement or differential birds' choice of S+, a finding which suggests that temporal factors were not important in controlling choice behavior.

These results are compatible with a conditioned reinforcement interpretation of delayed-reward learning (e.g., Grice, 1948; Spence, 1947). In a discrimination problem with delayed reward, stimuli immediately preceding reward acquire conditioned reinforcing properties. If these stimuli also occur immediately following the choice response, as they did for the reinstatement, differential, and reversed-cue birds, then a response to S+ or S- receives immediate conditioned reinforcement. Differential conditioned reinforcement that follows responding to $\mathrm{S}+$ and $\mathrm{S}-$ produces learning. Reinstatement, differential, and reversed-cue birds alike chose the stimulus followed by postresponse stimuli that were reinstated before reward, which allowed them to receive immediate conditioned reinforcement for that response. In particular, the latency data underscore the importance of the effect of immediate conditioned reinforce. ment in its control of choice responding, since reversed. cue birds responded as rapidly to $\mathrm{S}$ - as reinstatement and differential birds did to St. This conditioned rein forcement interpretation suggests that if the postresponse conditions immediately following $S-$ for reversed-cue birds had been similar to, but discriminable from, prereward stimuli, an initial S- preference might have yielded to an equal preference for $S+$ and $S-$.

Memory reactivation offers a plausible alternative account of these findings. Lett (1979), Roberts (1976), and Spear (1978) have all suggested that whenever there is long-delay learning, an association between the response and its contextual stimuli is formed. Presentation of similar contextual stimuli reactivates, or reinstates, memory of the response. The contiguity of the memory of the response and reward produces a preference for the correct response. The reinstatement and differential birds' data readily lend themselves to this interpretation. Memory of the response made to $S+$ is reactivated just before reward by stimuli identical to the postresponse stimuli. The striking results of the reversed-cue birds may likewise be due to memorial retrieval. These birds, like other birds, received equal exposure to $\mathrm{S}+$ and $\mathrm{S}$ - with their respective postresponse stimuli. Presentation of these postresponse stimuli contiguous with reward reactivated memory of the response to $S_{-}-$, producing a preference for $S-$. The reversed-cue birds' $S$ - preference was equally as strong as the reinstatement and differential birds' $\mathrm{S}+$ preferences.

A memorial reactivation account of the present study's data is not in conflict with a conditioned reinforcement account. In fact, memorial reactivation may be used to explain conditioned reinforcement if one 
assumes that a reactivated memory is a stimulus that functions in a fashion similar to that of an environmental stimulus. Therefore, a reactivated memory can acquire conditioned reinforcing properties. According to the memory reactivation account, the greater the similarity between the stimulus patterns at two different times, the greater the likelihood that the second pattern will reactivate memories of events contiguous to the first. Similarly, the conditioned reinforcement interpretation asserts that stimulus pattern similarity will enhance generalization of conditioned reinforcement from one pattern to the other.

The results obtained here are consistent with those of Trenholme and Baron's (1975) investigation of long. delay punishment in humans. Using a procedure similar to the reinstatement group's, they found that subjects chose the unpunished alternative even with long delays between responding and punishment. The results of both of these studies suggest that the obtained learning was governed by immediate reinforcement produced through a combined process of conditioned reinforcement and memory reactivation.

In contrast to the reversed-cue group's results, Bauer and Lawrence (1953) and Lawrence and Hommel (1961) found that rats learned to make a correct choice when black goalboxes followed white choice stimuli and white goalboxes followed black choice stimuli. However, both of these studies failed to provide strict cue reinstatement. Presumably, rats easily discriminate goalboxes from choice points. Therefore, an explanation of these two studies in terms of chaining or higher order conditioned reinforcement (e.g., Kelleher \& Gollub, 1962) seems quite feasible. In contrast, the results of the reversed-cue group vitiate the chaining interpretation here. Additionally, the absence of differential delay pecking tendencies, the nondifferential group's failure to learn, combined with the counterbalanced presentation of $\mathrm{S}+$ on the left and right keys all support the conclusion that chained conditioned reinforcement did not mediate learning in the present study.

Recently, Lieberman, McIntosh, and Thomas (1979) presented clear evidence of learning when briefly presented nondifferential postresponse cues were reinstated before trial outcomes. Control groups without these cues, but with otherwise similar nondifferential delays following correct and incorrect responses, did not learn. Lieberman et al. hypothesized that learning occurs under these conditions (i.e., Lett, 1974, but see also Roberts, 1976) because the salient postresponse stimulus causes the animal to "mark" or remember the response which preceded it. It is not clear from their analysis what the function of the reinstated prereward stimulus is. Perhaps this stimulus functions to place memory of the response made to the choice stimulus in contiguity with reward. If this is the case, then Lieberman et al.'s marking hypothesis seems to differ from Lett's (1979),
Roberts' (1976), and Spear's (1978) memorial interpretations, which emphasize the similarity of postresponse and prereward stimulus conditions. Lieberman et al.'s marking hypothesis seems to suggest that salient, but dissimilar, prereward stimuli will elicit a memory of a response marked by salient postresponse stimuli. It is not apparent how their marking theory accounts for the reversed-cue birds' $S$ - preference in the present experiment. That preference strongly indicates that the stimulus reinstated immediately before reward controlled choice responding. In any case, Lieberman et al.'s data suggest that the nondifferential group would learn if provided with additional brief nondifferential postresponse stimuli reinstated before trial outcome.

In preliminary work for this study, I increased the delay from 1 to $2 \mathrm{~min}$ and finally to $4 \mathrm{~min}$ for birds given differential, reinstatement, and nondifferential delay training. Other birds given reinstatement and nondifferential delay conditions began training with a 4-min delay. Birds trained with 4-min nondifferential delay conditions ceased pecking 4 to 8 days after completing an average of 14 trials each session. Birds trained with reinstatement and differential conditions selected St on more than $90 \%$ of the first 10 trials during the first five 4-min training sessions, completing 10 to 20 trials daily. After the fifth session, the birds com pleted fewer trials each day, and half of these birds eventually stopped pecking. Interestingly enough, if these birds made a choice response, it was always an $\mathrm{S}+$ response. Neither the memory reactivation nor a conditioned reinforcement account explains these data, for the reinforcing or retrieval properties of the delay stimuli should be equally effective at all delays. These findings are consistent with a substantial literature demonstrating the detrimental effect of increased delayed reward on performance (e.g., Cox \& D'Amato, 1977; see Renner, 1964, for a review) and suggest that pigeons do not peck stimuli signaling distant reward (Kelleher \& Gollub, 1962; Moore \& Fantino, 1975; Wasserman, Franklin, \& Hearst, 1974).

In conclusion, the present study provides very clear evidence of the strong influence exerted by the similarity of prereward and postresponse stimuli on choice respond. ing in long delayed-reward visual discrimination learning by pigeons. The data are readily interpretable from both the memorial and conditioned reinforcement accountsinterpretations which are viewed here as compatible.

\section{REFERENCES}

BaUer, F. J., \& LAwhinck, D. H. Influence of similarity of choice point and goal cues on discrimination learning. Journal of Comparative and Physiological Psychology, 1953, 46, 241-248.

Cox, J. K., \& D'Aмato, M. R. Disruption of overlearned discriminative behavior in monkeys (Cebus apella) by delay of reward. Animal Learning \& Behavior, 1977, 5, 93-98.

Fleshler, M., \& Hoffman, H. S. A progression for generating variable-interval schedules. Journal of the Experimental Analysis of Behavior, 1962, 5, 529-530. 
Grice, G. R. The relation of secondary reinforcement to delayed reward in visual discrimination learning. Journal of Experimental Psychology, 1948, 38, 1-16.

Kellaher, R. T., \& Goll.ub, L. R. A review of positive conditioned reinforcement. Journal of the Experimental Analysis of Behavior, 1962, 5, 543-597.

Lawrence, D. H., \& Hommel., L. The influence of differential goal boxes on discrimination learning involving delay of reinforcement. Journal of Comparative and Physiological Psychologv, 1961, 54, 552-555.

LETT, B. T. Visual discrimination learning with a $1-$ min delay of reward. Learning and Motivation, 1974, 5, 174-181.

LETr, B. T. Long-delay learning: Implication for learning and memory theory. In N. S. Sutherland (Ed.). Tutorial essays in psychologv: A guide to recent advances (Vol. 2). New York: Halsted Press, 1979.

Likberman, D. A., McIntosis, D. C., \& Thomas, G. V. Learning when reward is delayed: A marking hypothesis. Journal of Experimental Psychology: Animal Behavior Processes, 1979. 5. 224-242.

Moore, J., \& Fan'tino, E. Choice and response contingencies.
Jou nal of the Experimental Analysis of Behavior, 1975, 23. 339-347.

RenNeh, K. E. Delay of reinforcement: A historical review. Psychological Bulletin, 1964, 61, 341-361.

Roвerts, W. A. Failure to replicate visual discrimination learning with a 1-min delay of reward. Learning and Motivation, 1976, 7, 313-325.

SPEAR, N. E. The processing of memories: Forgetting and retention. New York: Erlbaum, 1978.

SpencF, K. W. The role of secondary reinforcement in delayed reward learning. Psychological Review, 1947, 54, 1-8.

Trenholme, I. A., \& Baron, A. Immediate and delayed punishment of human behavior by loss of reinforcement. Learning and Motivation, 1975, 6, 62-79.

Wasserman, E. A., Franklin, S. R., \& Hearst, E. Pavlovian appetitive contingencies: An approach versus withdrawal to conditioned stimuli in pigeons. Journal of Comparative and Physiological Psvchologv, 1974, 86, 616-627.

(Received for publication September 7, 1978: revision accepted February 20, 1980.) 